\title{
RELACIONAMENTO TEMPORAL ENTRE LUCROS TRIMESTRAIS E RETORNO DAS AÇÕES NO BRASIL
}

\section{TEMPORARY RELATIONSHIP BETWEEN QUARTERLY EARNINGS AND STOCK RETURN IN BRAZIL}

\author{
FRANCIANE DE OLIVEIRA ALVARENGA \\ Universidade Federal do Rio de Janeiro. Endereço: Rua Coronel Elpídio \\ Gonçalves da Costa, 587B, Vila Marchetti | 36307-246 | São João Del \\ Rei/MG | Brasil. \\ (1) http://orcid.org/0000-0002-4008-1429 \\ francianealvarenga@ufsj.edu.br
}

\section{LEILA BATISTA MELLO}

Universidade Federal do Rio de Janeiro. Endereço: Rua Filodentro, casa 133 - Condomínio Capim Melado, Freguesia | 22750-650 | Rio de Janeiro/RJ | Brasil.

(D) http://orcid.org/0000-0002-8478-9162

leilalbm63@gmail.com

\author{
MANOEL VITOR DE SOUZA VELOSO \\ Universidade Federal de Alfenas. Endereço: Rua Osvaldo Henrique Valadão, \\ 65/202, Rezende | 37623-370| Varginha/MG | Brasil. \\ (D) http://orcid.org/0000-0003-4118-6780 \\ manoel.souza@unifal-mg.edu.br
}

\author{
MARCELO ALVARO DA SILVA MACEDO \\ Universidade Federal do Rio de Janeiro. Endereço: Av. Pasteur, 250 - Sala \\ 250 - FACC/UFRJ, Urca | 22290-240| Rio de Janeiro/RJ |Brasil. \\ (D) http://orcid.org/0000-0003-2071-8661 \\ malvaro.facc.ufrj@gmail.com
}

\section{RESUMO}

Este estudo tem como objetivo analisar as propriedades de séries temporais dos lucros contábeis trimestrais e seu relacionamento com o preço (retorno) das ações nas empresas brasileiras com participações no Índice da Bolsa de Valores de São Paulo (Ibovespa) de 2010 a 2016, período após a adoção dos International Financial Reporting Standards (IFRS). Assim, das 58 empresas com ações ativas na data da coleta, foram analisadas 48 delas, uma vez que foram retiradas aquelas com ausência de informações nos referidos anos, totalizando, dessa forma, 1624 observações. Para isso, utilizou-se o modelo multivariado de séries temporais de vetores autorregressivos (VAR) e foram aplicados testes às séries temporais analisadas, a fim de verificar suas propriedades. Os achados da pesquisa apontaram que não há relação de longo prazo e nem causalidade entre os lucros trimestrais e o retorno das ações nas empresas estudadas. Além disso, foi observado que o retorno é mais sensível a mudanças nos lucros trimestrais do que o inverso. Por meio da decomposição da variância dos erros de previsão do lucro médio e do retorno médio, os resultados mostraram uma direção da causalidade no sentido de lucros trimestrais para retorno das ações. A função impulso-resposta permitiu observar, ainda, que o retorno é mais influenciado por choques do lucro do que o contrário, mostrando ajustamento a curto prazo. 
Palavras-chave: Lucros Contábeis Trimestrais. Preço das Ações. Séries Temporais.

\begin{abstract}
The objective of this study is to analyze the time series properties of quarterly accounting earnings and their relationship with the stock price (return) in Brazilian companies with shares in the Ibovespa from 2010 to 2016, after adoption of IFRS. Thus, of the 58 companies with shares active on the date of collection, 48 companies were analyzed, since those companies with no information in those years were withdrawn, totaling 1624 observations. For that multivariate model of time series of autoregressive vectors (VAR) was used and tests were applied to time series analyzed in order to verify their properties. The research findings pointed out that there is no long-term relationship and nor causality between quarterly earnings and stock returns in the companies studied. In addition, it has been observed that return is more sensitive to changes in quarterly earnings than the reverse. By decomposing the variance of the forecast errors of average earnings and average stock return, the results showed a direction of causality toward quarterly earnings for stock returns. The impulse-response function also allowed us to observe that stock return is more influenced by earnings shocks than the opposite, showing a short-term adjustment.
\end{abstract}

Keywords: Quarterly Accounting Earnings. Stock Price. Time series.

\title{
1 INTRODUÇÃO
}

Em um mercado cada vez mais desenvolvido e complexo, a contabilidade assume papel de suma importância para os usuários externos, no que tange à capacidade de fornecer informações que os influenciem em suas decisões - também chamada de informatividade ou conteúdo informacional.

Considerando que os relatórios contábeis são a principal fonte de informações econômico-financeiras das empresas, a adoção das normas dos International Financial Reporting Standards (IFRS) teve como principal objetivo garantir a melhoria nas informações divulgadas, tornando-as mais compreensíveis, relevantes, confiáveis e comparáveis - ou seja, úteis para o processo decisório dos usuários, principalmente para aqueles que são externos à empresa (Antunes, Grecco, Formigoni, \& Mendonça Neto, 2012).

As empresas que possuem conteúdo informacional em um mercado dito eficiente, fazem com que as informações divulgadas interfiram na expectativa dos investidores em relação aos seus retornos futuros e afetem, consequentemente, o valor atual da empresa. Nos últimos 50 anos, esse tema tem motivado diversos pesquisadores a comprovar tal relação, embora pesquisas apontem resultados contrários desde seu surgimento (Ball, \& Brown, 1968; Kothari, 2001; Lev, \& Amir, 1989).

Antunes et al. (2012) mencionam a importância da análise das informações geradas e divulgadas após a adoção dos IFRS, uma vez que trouxeram significativas modificações no reconhecimento, mensuração e divulgação dos elementos patrimoniais e de desempenho. Assim, são esperadas implicações para os diferentes padrões de indicadores econômicos, financeiros e de desempenho, extraídos das novas demonstrações contábeis, tornando importante a revisão dos parâmetros atuais de indicadores e do próprio processo de análise, principalmente dos analistas financeiros e profissionais de finanças.

Este estudo tem como objetivo analisar as propriedades de séries temporais dos lucros contábeis trimestrais e seu relacionamento com o preço (retorno) das ações nas empresas brasileiras com participações no Índice da Bolsa de Valores de São Paulo (Ibovespa) de 2010 a 2016, período após a adoção dos IFRS. Acredita-se que a contabilidade após a adoção dos IFRS 
deixou de ser elaborada com fins meramente fiscais e para a obtenção de crédito, passando a visar a essência sobre a forma. Tal fato refletiria em uma maior relação entre lucro e retorno, uma vez que houve alterações na mensuração do lucro, tornando-os mais tempestivos e confiáveis.

Foster (1977) argumentou que a pesquisa de séries temporais é importante para as áreas de contabilidade e finanças, como a "literatura sobre suavização": os gestores possivelmente conhecem o processo estocástico que gera a série contábil ao tomar decisões sobre suavização.

Kothari (2001, p. 148) afirma que o interesse nas propriedades das séries temporais de ganhos trimestrais surgem por pelo menos por quatro razões: 1) os ganhos trimestrais são sazonais em muitas indústrias devido à natureza estacional da sua atividade principal; 2) os ganhos trimestrais são mais oportunos, de modo que, com uso de suas projeções como proxies, para a expectativa do mercado, é provável que seja mais preciso do que usar uma previsão de ganhos anuais estancada; 3) O Generally Accepted Accounting Principles (GAAP) exige que o período de relatório trimestral seja parte integrante do anual, de modo que as empresas são obrigadas a estimar as despesas operacionais anuais e alocá-las a períodos trimestrais (mais importante, os resultados trimestrais são potencialmente mais poderosos para testar a hipótese da teoria contábil positiva e da pesquisa de mercado de capitais); e 4) há quatro vezes mais ganhos trimestrais do que ganhos anuais, o que significa requisitos de disponibilidade de dados menos rigorosos, utilizando dados trimestrais para obter o mesmo grau de precisão de previsão.

Entender melhor o vetor de causalidade entre lucro e preço é de suma importância para o mercado brasileiro, uma vez que os investidores buscam constantemente novas maneiras de prever com mais precisão os resultados futuros das empresas. Os resultados de uma análise sobre a série temporal do retorno e do preço das ações permitirão que os investidores verifiquem se existem indícios de que a hipótese de eficiência e a importância da contabilidade servem como mecanismos de transmissão de conteúdo informacional, e se eles se sustentam no mercado brasileiro.

Além disso, quanto ao período analisado, considera-se que após a convergência completa das normas contábeis em 2010, a grande maioria das empresas apurou aumentos expressivos tanto no lucro, quanto no patrimônio líquido, em decorrência dessa convergência. Assim, o desempenho econômico efetivo das empresas brasileiras era superior ao que poderia transparecer pela análise de relatórios produzidos anteriormente. (Santos, 2012).

Dessa forma, Santos (2015) aponta que os relatórios contábeis no padrão IFRS refletem mais adequadamente a realidade econômica das empresas, necessitando, assim, de maior atenção dos analistas e estudiosos de séries temporais que abranjam esse período de transição de normas.

\section{REFERENCIAL TEÓRICO}

Vários estudos têm utilizado séries temporais para analisar a relação entre lucro e retorno tanto a nível mundial, quanto no mercado brasileiro. Cada trabalho possui uma abordagem, visão e forma de análise dos dados contábeis que se diferencia deste estudo; sendo um dos focos deste artigo a discussão dos resultados obtidos após a implementação dos IFRS no Brasil para as empresas pertencentes ao Ibovespa.

Bem antes da implementação dos IFRS, Foster (1977) examinou o comportamento temporal das séries trimestrais de lucros, vendas e despesas de 69 empresas durante o período de 1946 a 1974. Para isso, adotou uma metodologia de séries temporais Box-Jenkins. Com base na inspeção da função de autocorrelação transversal, concluiu que cada série tem uma componente adjacente de trimestre a trimestre e uma componente sazonal. Os resultados de previsão em uma etapa avançada revelaram que esses dois componentes podem ser modelados com sucesso no nível de empresa individual. O uso de vários modelos de previsão trimestral na análise de preços de segurança também é examinado. Os resultados são consistentes com o ajuste do mercado para a sazonalidade nos ganhos trimestrais, na interpretação da variação de cada trimestre de ganhos. 
Já O’Hanlon (1991) verificou se os retornos contábeis (ROE) teriam impactos nos retornos das ações, ou vice-versa. Para isso, utilizou a metodologia Teste de Causalidade Granger em 222 empresas do Reino Unido, com dados anuais de 1968 a 1987, e os resultados apontaram que há causalidade bidirecional entre as variáveis. O ROE exerce mais influência sobre o retorno das ações do que o contrário.

Diferentemente, Martikainen e Puttonen (1993), que investigaram a eficiência informacional dos mercados de ações, focando na relação entre os preços das ações, os ROE e os fluxos de caixa das empresas, fizeram uma análise de cointegração em 21 empresas da Finlândia, com dados anuais de 1974 a 1989. Chegando à conclusão que os retornos das ações influenciam os ROE, e não o contrário. Tal resultado foi diferente do apresentado por O'Hanlon (1991). Além disso, a análise de cointegração indicou que ao incluir a correção de erro com base em variáveis de preço não estacionárias, melhorou significativamente a associação observada entre as variáveis contábeis e de mercado de ações.

Jindrichovska (2001) investigou a relação entre os dados contábeis e o retorno do preço de mercado das ações das empresas listadas na Bolsa de Valores de Praga (PSE), por meio de uma análise de cointegração. Foram analisadas 63 empresas industriais da República Tcheca entre de 1993 a 1998. As evidências demonstraram a existência de relação entre as variáveis estudadas para medições de um ano ou mais.

Abordando a existência da relação entre variáveis contábeis e preços, Kothari (2001) expõe um estudo de associação que testa a correlação positiva entre medida de desempenho contábil (por exemplo, lucros ou fluxo de caixa das operações) e retornos das ações, ambos medidos em períodos de tempo atuais relativamente longos, por exemplo, um ano. Uma vez que os participantes do mercado têm acesso a muitas fontes mais oportunas de informações sobre a capacidade de geração de fluxo de caixa de uma empresa, os estudos de associação não presumem que os relatórios contábeis são as únicas fontes de informação para os participantes do mercado. $\mathrm{O}$ autor salienta que não existe qualquer relação causal entre a informação contábil e o preço da ação, e que o objetivo foi testar com que rapidez as medidas contábeis capturam as mudanças no conjunto de informações que se refletem nos retornos das ações, ao longo de um determinado período.

Em linha com as pesquisas anteriores, Galdi e Lopes (2008) analisaram a relação entre o lucro contábil e o preço das ações, por meio de uma análise de cointegração em 41 empresas da América Latina. Em complemento ao teste de cointegração, investigaram a causalidade de Granger entre o lucro e o preço das ações. Em seus resultados, os autores evidenciaram que existe um relacionamento de longo prazo entre o lucro e os preços das ações para a maior parte das empresas analisadas.

Também Tswei (2013) avaliou a relação entre os dados contábeis e o retorno, por meio do preço no mercado das ações, $\mathrm{O}$ autor avaliou empresas de Taiwan com dados trimestrais de 1981 a 2012, por meio de vetor de correção de erros (VEC). Ele observou baixa relevância nas análises de longo prazo, em contraste com maior relevância no curto prazo.

No Brasil, Lopes (2002, p. 58-59) relata que "as evidências a respeito da América Latina na literatura contábil internacional são praticamente inexistentes. A literatura nacional também vem apresentando poucas contribuições ao estudo empírico do papel da contabilidade no mercado brasileiro".

No estudo de Lopes (2003) sobre a causalidade entre lucro e retorno, o autor encontrou evidências de que, para defasagens pequenas (um a três períodos), há relação de causalidade no sentido de lucro para retorno, porém essas conclusões não puderam ser estendidas, pois foram analisadas somente duas empresas.

Pouco antes da implementação dos IFRS no Brasil, Van Doornik (2007) verificou o relacionamento entre variáveis contábeis e macroeconômicas que previa o comportamento econômico-financeiro de uma empresa brasileira, utilizando VAR. O estudo foi realizado na 
Petróleo Brasileiro S.A. (Petrobrás) e apontou que VAR possuem maior capacidade preditiva do que o sistema de equações múltiplas.

Com achados semelhantes a O'Hanlon (1991), no Reino Unido, Costa Jr., Meurer e Cupertino (2007) verificaram, em empresas brasileiras, o relacionamento entre as séries dos ROE e dos RET por meio da causalidade de Granger. O estudou foi realizado em 97 empresas listadas na BM\&FBovespa com dados trimestrais de 1995 a 2007. Os resultados mostraram que há causalidade bidirecional entre as variáveis. Assim como O'Hanlon (1991), no período de 1968 a 1987, os autores tiveram resultados que evidenciaram que o ROE exerce maior influência sobre o retorno das ações do que o contrário.

Já Costa Jr., Martinez, Coelho e Cupertino (2008) analisaram as propriedades das séries temporais dos lucros trimestrais das empresas brasileiras de 1995 a 2006, e verificaram que existe uma relação negativa entre as variações sucessivas de lucros trimestrais - ou seja, empresas que aumentaram seus lucros acima da média, num determinado período, tiveram tendência a variar menos que a média nos períodos subsequentes.

Sonza e Kloeckner (2009) verificaram o relacionamento, de curto e longo prazo, entre o lucro contábil e o respectivo preço das ações, utilizando o método de análise de cointegração e do VEC para 20 empresas da BM\&FBovespa, com dados trimestrais de 1990 a 2008. Em seus resultados, os autores apontaram que os lucros influenciam o preço das ações no longo prazo; seus achados divergem em alguns pontos ao apresentado por Costa Jr., Meurer e Cupertino (2007).

Utilizando dados anteriores à implementação dos IFRS no Brasil, Pimentel e Lima (2010) analisaram as propriedades de séries temporais dos lucros trimestrais de 1995 a 2009 , de 71 empresas brasileiras listadas na bolsa de valores, utilizando modelo autorregressivo. Os resultados apontaram uma relação significativa entre os ganhos e os preços das ações, porém a direção da causalidade não é geralmente definida - o que sugere que a relação lucro-retorno deva ser analisada à nível de empresa específica. Os autores também mencionam que o aumento dos itens extraordinários nos resultados dos últimos anos enfraqueceu ainda mais a relação entre os ganhos de curto prazo não esperados e as revisões nas expectativas sobre os ganhos nos períodos futuros, conforme capturado no período de anúncio de mudança no preço. Tais itens extraordinários, na demonstração de resultados, não foram mais permitidos a partir da adoção dos IFRS.

Também anterior à convergência para as normas internacionais, Campos, Lamounier e Bressan (2012) verificaram, por meio do teste de causalidade de Granger, o relacionamento entre as séries trimestrais dos lucros contábeis e os RET de empresas brasileiras com ações em bolsa, que apresentam níveis diferentes de exigências de divulgação. A amostra analisada foi composta por 75 empresas listadas na BM\&FBovespa, durante o período de 1995 a 2010. As variáveis analisadas foram os ROE e os RET. Não foi constatado que a causalidade entre ROE e RET é maior para empresas que possuem maior nível de exigência de divulgações das informações contábeis, permitindo inferir que os lucros líquidos das empresas que divulgam mais informações contábeis não possuem maior causalidade com o RET do que as demais empresas nesse caso ainda não havia a necessidade de maior divulgação e disclosure nos dados contábeis.

Utilizando períodos anterior e posterior à implementação das normas IFRS, Brugni, Favero, Flores e Beiruth (2015) avaliaram 36 empresas do mercado de capitais brasileiro no período de 2003 a 2013, buscando investigar se existiam incentivos para a informação contábil divulgada seguir o preço das ações, e não o contrário. Para isso, inicialmente explorou-se a relação no tempo entre o componente-surpresa dos lucros e o preço das ações, por intermédio da aplicação do teste de causalidade de Granger. Posteriormente, utilizou-se a técnica de regressão logística para identificar possíveis incentivos que pudessem aumentar a probabilidade de ocorrência do vetor de causalidade, no sentido de Granger, do preço para o lucro. Os resultados indicam que, das empresas analisadas, 11 possuem o componente-surpresa do lucro Granger - 
causando preço - e em 10 o mercado consegue antecipar, no curto prazo, o componente-surpresa do lucro futuro.

Também Deorce, Carrasco Gutierrez, Reis e Castro (2018) investigaram, no âmbito do mercado acionário brasileiro, a relação de causa e efeito entre o ROE e o RET no Brasil, analisando a precedência temporal e procurando evidências sobre a capacidade preditiva. Por meio do teste de causalidade de Granger, analisaram a relação de causa e efeito entre o ROE e o RET das empresas listadas na BM\&FBovespa, no período de 1995 até 2009 - ou seja, anterior à implementação das normas internacionais. Os resultados indicaram que, em geral, não existem evidências de causalidade entre o RET e o ROE em nenhuma direção, não sendo possível apontar, nesses casos, precedência temporal, o que demonstra o baixo poder de melhoria da variância da previsão com a inclusão de uma das variáveis.

Diante de poucos estudos com séries temporais após a implementação dos IFRS no Brasil, utilizando os pressupostos teóricos e as evidências empíricas apresentados e discutidas na seção anterior, cabe questionar se tais evidências se mantêm sobre a relação entre os lucros contábeis e os retornos/preços das ações, com amostras posteriores à implementação dos IFRS no Brasil. Portanto, as hipóteses desta pesquisa são:

H1: Há relação de longo prazo entre os lucros trimestrais e o retorno das ações das empresas brasileiras com participações no Ibovespa no período de 2010 a 2016 - ou seja, pós implementação dos IFRS.

H2: Há causalidade entre os lucros trimestrais e o retorno das ações das empresas brasileiras com participações no Ibovespa no período de 2010 a 2016 - ou seja, pós implementação dos IFRS.

\section{METODOLOGIA}

\subsection{Tipo de pesquisa}

Considerando que a pesquisa tem características inerentes à tradição positiva da Contabilidade, este trabalho adota uma abordagem metodológica empírico-analítica de forma a buscar as propriedades das séries temporais dos lucros trimestrais em relação ao retorno do preço das ações.

No intuito de atender aos objetivos da pesquisa, este estudo pode ser classificado como investigação explicativa. Para Gil (2002, p. 42), a pesquisa explicativa tem por finalidade "aprofundar o conhecimento da realidade e explicar o porquê das coisas [...] este tipo de pesquisa tem como preocupação central identificar os fatores que determinam ou que contribuem para a ocorrência dos fenômenos".

A pesquisa tem natureza quantitativa quando se utiliza as técnicas de coleta, tratamento e análise de dados, que de acordo com Oliveira (2011, p. 81), "a pesquisa quantitativa se utiliza de métodos estatísticos, como a estatística descritiva para comprovar hipóteses”. Martins (2002) corrobora afirmando que esse tipo de pesquisa busca privilegiar estudos práticos e se preocupar com relações causais entre variáveis.

Quanto aos procedimentos técnicos utilizados, esta pesquisa pode ser classificada como bibliográfica, uma vez que utiliza material já elaborado por outros autores, como livros e artigos científicos. Para Marconi e Lakatos (2002, p. 71), "a pesquisa bibliográfica não é mera repetição do que já foi dito ou escrito sobre certo assunto, mas propicia o exame de um tema sob novo enfoque ou abordagem, chegando a conclusões inovadoras". Além disso, é considerada como expost-facto que, segundo Gil (2002, p. 49) consiste em uma investigação sistemática e empírica, na qual "o pesquisador não tem controle direto sobre as variáveis independentes". 


\subsection{Coleta de dados e variáveis selecionadas}

A base de dados utilizada neste estudo foi gerada no dia 13 de abril de 2017, por meio de informações contidas na base de dados do software Economática. Foi utilizada uma série histórica compreendida entre os anos de 2010 a 2016, para empresas listadas na bolsa de valores e que tivessem participações no Ibovespa, na data da coleta. Assim, foram selecionadas 58 empresas com ações ativas na carteira, no momento da coleta de dados, de 16 setores e de diversos tamanhos.

Tendo este estudo o objetivo de analisar as propriedades de séries temporais dos lucros contábeis trimestrais e seu relacionamento com o preço (retorno) das ações nas empresas brasileiras com participações no Ibovespa de 2010 a 2016, a análise das variáveis lucro por ação (LPA) e o retorno da ação (RET) se baseou em dados trimestrais, iniciando no primeiro trimestre de 2010, até o quarto trimestre de 2016, totalizando 28 trimestres.

Considerando 58 empresas no período entre 2010 e 2016, foram utilizadas apenas 45 delas, uma vez que foram retiradas aquelas com ausência de informações nos referidos anos, totalizando, assim, 1624 observações.

Ball e Watts (1972), citados por Costa Jr. et al. (2008), salientam que o procedimento de restringir as observações às empresas, com dados existentes para a maior parte da série, tem como consequência concentrar as análises apenas em firmas "sobreviventes" e, desse modo, os decréscimos observados nas séries de lucros serão poucos e subestimados.

Os resultados contábeis trimestrais consistem em ganhos acumulados em três meses (janeiro-março, abril-junho, julho-setembro e outubro-dezembro).

O preço da ação (P) é o preço oficial de fechamento em moeda local, ajustado por dividendos. Assim, foi selecionado o primeiro preço disponível para a data, considerando uma janela de cinco dias úteis. Posteriormente, foi calculado o RET trimestralmente da seguinte forma:

$$
\mathrm{RET}=\ln \left(\frac{\mathrm{P}_{\mathrm{t}}}{\mathrm{P}_{\mathrm{t}-1}}\right)
$$

Onde: $\ln =$ logaritmo natural

$\mathrm{Pt}=$ é o preço ajustado por dividendos no final do período $\mathrm{t}$

Os retornos trimestrais foram calculados considerando os intervalos de março-maio, junho-agosto, setembro-novembro e dezembro-fevereiro, para o primeiro, segundo, terceiro e quarto trimestres, respectivamente. Esse método também é utilizado por Pimentel e Lima (2010) e tem como objetivo capturar qualquer reação de retorno associado ao anúncio de ganhos para o trimestre.

Considerando que foram analisadas apenas as empresas que possuíam informações para todos os períodos, e para não subestimar os resultados, foi realizada uma análise conjunta, usando o lucro médio das empresas em cada trimestre, com o intuito de saber a relação entre lucro e retorno de 2010 a 2016, após a adoção dos IFRS. Assim, consolidando as médias trimestrais de todas as empresas, e não de cada uma em separado, totalizaram 28 trimestres em sete anos.

\subsection{Instrumento de análise}

Para alcançar o objetivo proposto, utilizou-se o modelo multivariado de séries temporais de VAR, além disso, foram aplicados testes às séries temporais analisadas, a fim de verificar suas propriedades. O modelo VAR é muito utilizado para capturar a evolução e as interdependências entre múltiplas series temporais, generalizando o conceito de modelos autorregressivos univariados para um espaço multivariado. 
O método VAR descreve uma função linear da evolução passada de um conjunto de variáveis sobre um mesmo período de tempo. Dessa forma, Caiado (2002) afirma que esses modelos examinam relações lineares, entre cada variável, e os valores defasados dela própria e de todas as demais variáveis; eles tomam em consideração a existência de relações de interdependência entre as variáveis e permitem avaliar o impacto dinâmico das perturbações aleatórias sobre o sistema delas - o que os tornam particularmente úteis e eficientes na previsão do comportamento futuro de séries temporais interrelacionadas. Para isso, todas as variáveis incluídas são consideradas como endógenas, formando um sistema de equações estimadas pelo Método dos Mínimos Quadrados Ordinários (MQO). (Gujarati, 2011)

Uma condição básica para a aplicação da metodologia VAR é que a série temporal seja estacionária, ou seja, não apresente tendência ou sazonalidade. De acordo com Gujarati (2011), uma série temporal é estacionária quando sua média e variância forem constantes ao longo do tempo e o valor da covariância entre dois períodos de tempo depender apenas da distância ou defasagem entre os dois períodos, e não do período de tempo efetivo em que a covariância é calculada.

A primeira etapa do trabalho consistiu em verificar se a série temporal é estacionária. Foi feito um estudo da função de autocorrelação das séries para saber se para as 27 defasagens das séries em questão se encontravam dentro dos limites de um intervalo de confiança de $95 \%$ para a correlação entre seus valores. O teste de Dikey-Fuller Aumentado também foi usado para verificar a estacionariedade dessas séries.

Após a verificação da estacionariedade, procedeu-se aos testes de cointegração de EngleGranger. Existindo relações de cointegração entre as séries, diz-se que elas apresentam relação linear estável no longo prazo, ou de equilíbrio, entre elas (Gujarati, 2011).

$\mathrm{Na}$ etapa seguinte, realizou-se o teste de causalidade de Granger (1969). Esse teste visa superar as limitações do uso de simples correlações entre variáveis, pois correlação não implica por si só em causalidade (relação de causa e efeito). Assim, uma variável X causa outra variável $Z$, no sentido de Granger, se a observação de $X$, no presente ou no passado, ajuda a prever os valores futuros de Z, para algum horizonte de tempo. Carneiro (1997) afirma que a identificação de uma relação estatística entre duas ou mais variáveis, por mais forte que seja, não pode estabelecer uma relação causal entre elas. Para ele, qualquer relação de causalidade deve se originar de fora da estatística, baseando-se, fundamentalmente, em alguma teoria já estabelecida ou até mesmo no senso comum. A relação de causalidade entre as variáveis é fundamental dentro da análise de séries temporais, pois, apesar de a análise de regressão lidar com dependência de uma variável em relação a outras, essa dependência não implica relação de causalidade. Como o futuro não pode prever o passado, se a variável $\mathrm{X}$ causa (no sentido de Granger) a variável $\mathrm{Y}$, então mudanças em $\mathrm{X}$ devem preceder mudanças em $\mathrm{Y}$.

Por último, será investigada a função de impulso-resposta (FIR) e a decomposição da variância, as quais permitem verificar as relações (efeitos) de choques de lucro no retorno e viceversa. Enders (2010) menciona que, por meio do instrumental de impulso-resposta, é possível visualizar a resposta de determinada variável a um choque específico nas inovações (resíduos) do modelo (aumento de uma unidade), enquanto os demais choques permanecem constantes. Além disso, é possível observar em quanto tempo o choque se dissipa para retornar à trajetória estável de longo prazo (correção de erros).

Para a estimação dos testes e dos modelos apresentados anteriormente, utilizou-se o software estatístico Gretl. Na seção seguinte, são apresentados e discutidos os principais resultados obtidos pelas estimações expostas na metodologia proposta.

\section{APRESENTAÇÃO E ANÁLISE DOS RESULTADOS}

No intuito de analisar as propriedades de séries temporais dos lucros contábeis trimestrais e seu relacionamento com o preço (retorno) das ações nas empresas brasileiras com participações 
no Ibovespa, utilizou-se o modelo multivariado de séries temporais de VAR e foram aplicados testes às séries temporais analisadas, a fim de verificar suas propriedades. Vale ressaltar que o Ibovespa é formado pelas ações das empresas com maior liquidez e maior volume financeiro negociado de todo o volume de negócios da bolsa, sendo considerado o principal índice do mercado de ações, servindo ainda como referência para investidores ao redor do mundo.

Iniciou-se a análise descrevendo as séries do lucro médio e retorno médio trimestrais das empresas, conforme as Figuras 1A e 1B. Por meio das figuras, pode-se perceber, inicialmente, que o comportamento das séries trimestrais não coincidem.

A

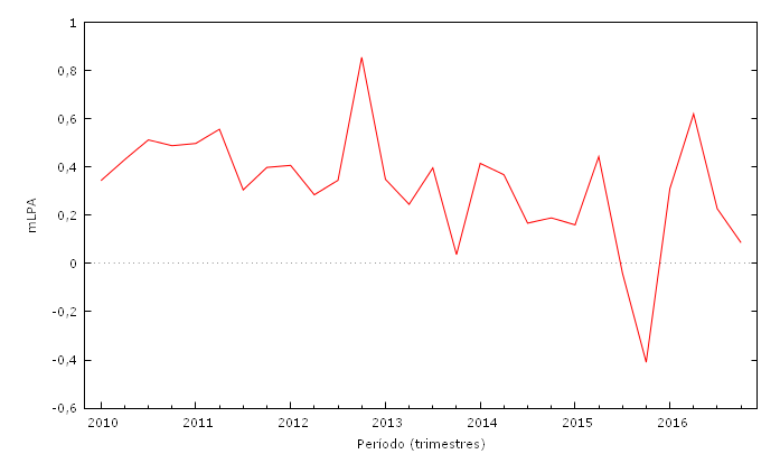

B

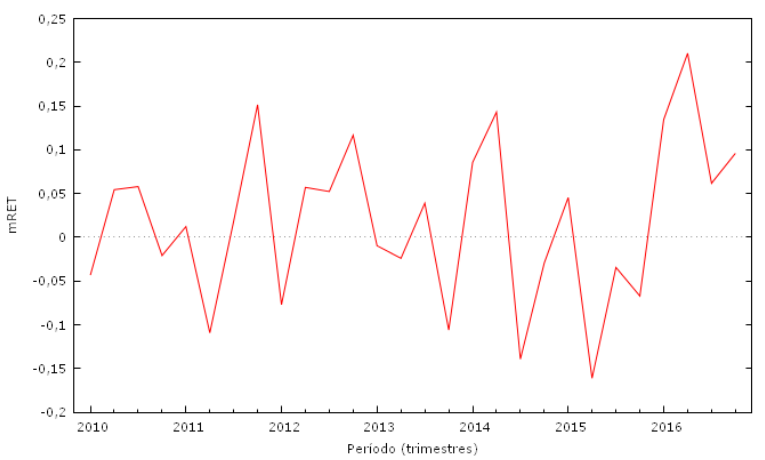

Figura 1. Série (A) do lucro médio trimestral (mLPA) e (B) do retorno médio trimestral (mRET) de 2010-1 a 2016-4

Fonte: Elaborado pelos autores (2017).

Em seguida, foram gerados os correlogramas das séries em questão para verificar sua estacionariedade, como mostra a Figura 2.

A

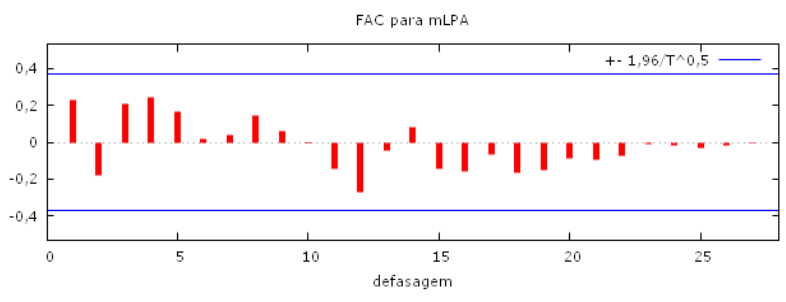

FACP para $\mathrm{MLPA}$

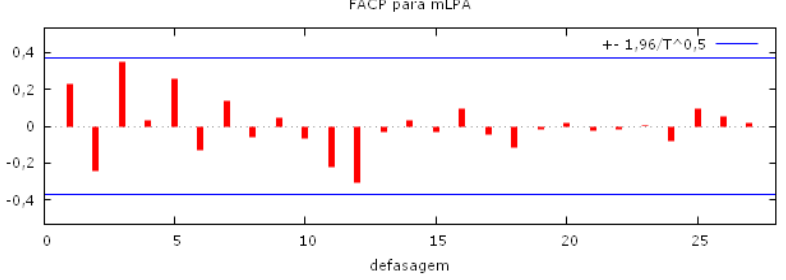

B
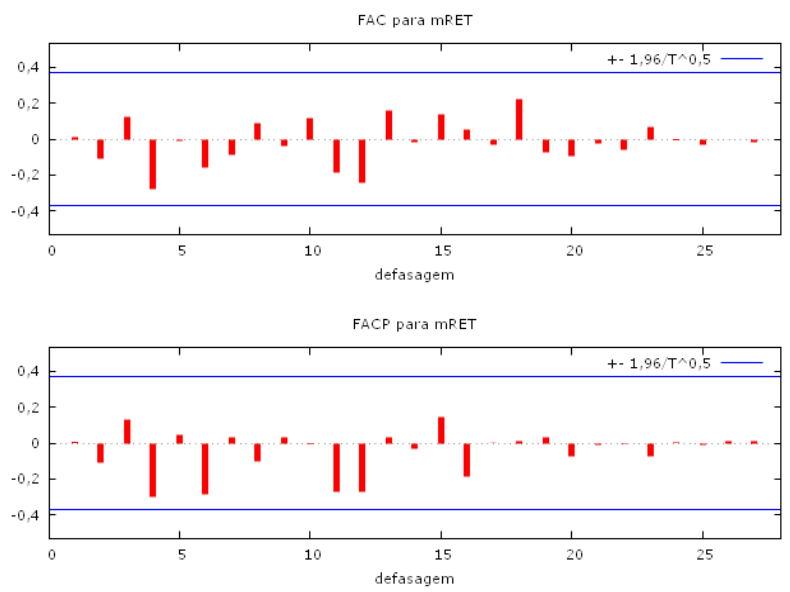

Figura 2. (A) - Gráfico de Autocorrelação (FAC) e autocorrelação parcial (FACP) do lucro médio trimestral; (B) - Gráfico de Autocorrelação (FAC) e autocorrelação parcial (FACP) do retorno médio trimestral; de 2010-1 a 2016-4.

Fonte: Elaborado pelos autores (2017).

Os correlogramas permitiram ver que as correlações nas 27 defasagens possíveis estão dentro das margens de confiança ao nível de 95\%, informando que as séries são estacionárias. O teste de raíz unitária de Dickey-Fuller foi feito, confirmando que as séries têm raíz unitária. Sendo assim, seria preciso trabalhar com as primeiras diferenças das séries para que elas fossem consideradas estacionárias. Decidiu-se não diferenciar as séries pelo fato de que os correlogramas já apresentaram autocorrelações não significativas (estatisticamente nulas), 
indicando estacionariedade, e também porque, com as primeiras diferenças, reduziria-se a amostra, que já é pequena, em uma observação, podendo reduzir ainda mais as chances de constatar relação de causalidade ou de longo prazo entre as séries.

Com a intenção de saber se as séries têm relação de longo prazo, foi feito o teste de cointegração de Engle-Granger (Tabela 1). Para que as séries sejam cointegradas, testes de raíz unitária são feitos nas séries do lucro, do retorno e dos resíduos da regressão cointegrante (mLPA em função de mRET). As séries do lucro e do retorno serão cointegradas se o lucro e o retorno médio trimestrais tiverem raíz unitária (p-valor>nível de significância) e os resíduos não tiverem (p-valor<nível de significância).

Tabela 1

Teste de cointegração de Engle-Granger ao nível de 5\% de significância

\begin{tabular}{l|l}
\hline Séries & P-valor do teste de raiz unitária \\
\hline mLPA & 0,3906 \\
\hline mRET & 0,1256 \\
\hline Resíduos da regressão cointegrante & 0,8564 \\
\hline Fonte: Elaborado pelos autores (2017)
\end{tabular}

Fonte: Elaborado pelos autores (2017).

Conforme a Tabela 1, as séries mLPA, mRET e a séries dos resíduos da regressão cointegrante têm raiz unitária (p-valor >0,05). Dessa forma, pode-se dizer que as séries não são cointegradas, indicando que elas não têm relação a longo prazo, mas sim relação a curto prazo, rejeitando, portanto, a primeira hipótese desse estudo.

O teste de causalidade de Granger pode ser verificado na Tabela 2.

Tabela 2

Teste de causalidade de Granger

\begin{tabular}{cccl}
\hline Direção & Defasagens & P-valor (teste $\mathbf{F})$ & Decisão \\
\hline $\mathrm{mLPA} \rightarrow \mathrm{mRET}$ & 3 & 0,2034 & mLPA não causa granger mRET \\
\hline $\mathrm{mRET} \rightarrow \mathrm{mLPA}$ & 3 & 0,1932 & mRET não causa granger mLPA \\
\hline
\end{tabular}

Fonte: Elaborado pelos autores (2017).

Pode-se verificar na Tabela 2 que, como o teste de causalidade não foi significativo para ambas direções, não foi constatado a causalidade entre as séries. Logo, rejeita-se a segunda hipótese também. Vale ressaltar que, como tem-se apenas 28 observações nas séries em questão, pode ser que os testes de cointegração e de causalidade estejam sendo subestimados.

Porém, como se tem a estacionariedade das duas séries, procedeu-se com o ajuste VAR(d) bivariado, em que "d" é o número de defasagens escolhido dentre os indicados, por algum critério de informação. Para isso, foram usados os critérios de informação de Akaike (AIC), o Bayesiano (BIC) e o de Hannan-Quinn (HQC) para a seleção do número de defasagens adequado para o ajuste VAR. A Tabela 3 apresenta o resultado para tal seleção.

Tabela 3

Seleção de defasagens para o ajuste do modelo de vetores autoregressivos (VAR)

\begin{tabular}{ccc}
\hline Critério & Valor & Defasagens \\
\hline AIC & $-5,0225$ & 8 \\
BIC & $-3,3298$ & 8 \\
\hline HQC & $-4,6921$ & 8 \\
\hline
\end{tabular}

Fonte: Elaborado pelos autores (2017). 
O AIC apresentou o menor valor, devendo escolher o número de defasagens indicado por esse critério, porém, os outros critérios também indicaram ser oito o número de defasagens, confirmando ser oito o número de defasagens indicado - VAR(8).

Após essa etapa, foram feitos ajustes de VAR, sendo que o primeiro a ser testado foi o VAR(8), como indicado pelos critérios na seleção de defasagens. Porém, o modelo VAR(8) não apresentou resíduos distribuídos como ruído branco, não sendo estacionários. Tentou-se o ajuste também para "d" assumindo valores $(7,6,5,4,2$ e 1), todos apresentando resíduos não estacionários. Com exceção do modelo VAR(3), que apresentou resíduos estacionários, conforme pode-se ver na Tabela 4, em que é apresentado o teste de autocorrelação de Ljung-Box para estacionariedade dos resíduos a cada uma das equações do modelo ajustado VAR(3), testando a H0: os resíduos são estacionários, usando a estatística Q com distribuição quiquadrado.

Tabela 4

Teste de Ljung-Box de autocorrelação dos resíduos

\begin{tabular}{ccc}
\hline Variável dependente & Estatística $\mathbf{Q}$ & P-valor \\
\hline mLPA & 8,9535 & 0,2034 \\
\hline mRET & 10,2522 & 0,1932 \\
\hline
\end{tabular}

Fonte: Elaborado pelos autores (2017).

Com a identificação e o ajuste do modelo, procedeu-se as análises das funções impulsoresposta e da decomposição da variância. Os resultados são apresentados na Figura 3A e 3B e na Tabela 4.

Nas funções de impulso-resposta (FIR), simulou-se um choque não antecipado no retorno ao lucro, e no lucro ao retorno. A Figura 3A apresenta a função impulso-resposta para o lucro e a 3B para o retorno. As funções são representadas por sua estimativa pontual e a área em cinza corresponde a um intervalo de confiança de $95 \%$.

A

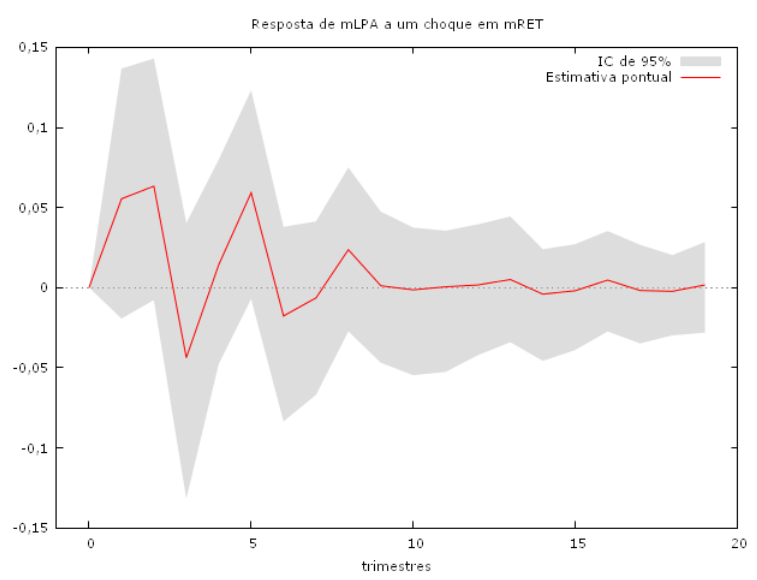

B

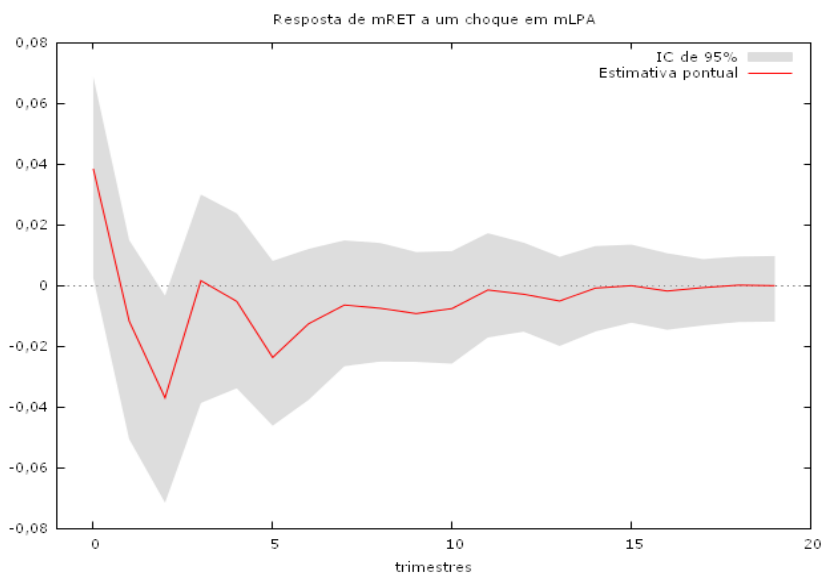

Figura 3. (A) - FIR do lucro médio a um choque no retorno; (B) - FIR do retorno médio a um choque no lucro.

Fonte: Elaborado pelos autores (2017).

Observa-se na Figura 3A que a resposta do LPA ao choque no retorno se estabiliza, aproximadamente, no prazo de nove períodos (dois anos e um trimestre) - o que, para uma série com 28 trimestres, indica um ajustamento de curto prazo, não tendo mais efeito sobre o lucro nos trimestres seguintes. Já na Figura 3B, o resultado da função impulso-resposta do retorno a um choque no lucro sugere a ocorrência de um efeito negativo sobre o retorno, caindo a partir do 
segundo trimestre e permanecendo até o décimo segundo trimestre (três anos), aproximadamente, tornando inefetivo a partir do quarto ano, quando a curva se torna uniforme. No entanto, verifica-se que o período de ajustamento é superior ao da Figura 3A, indicando que o retorno é mais influenciado por choques do lucro do que o contrário, o que pode, caso a análise tivesse um período maior, ser um indicativo de relação a longo prazo. Mas, no período estudado, o que se pode observar é um ajustamento a curto prazo.

Tal resultado lembra Kothari (2001) em seu estudo, quando ressaltou que não existe qualquer relação causal entre a informação contábil (lucro trimestral) e o preço da ação (retorno). Mas, utilizando as séries temporais, o objetivo seria verificar com que rapidez as medidas contábeis capturam as mudanças e as refletem no preço das ações num determinado período.

Fato que também corrobora os resultados da pesquisa de Tswei (2013), que avaliou a relação entre os dados contábeis e o retorno no preço de mercado das ações. Foram avaliadas empresas de Taiwan com dados trimestrais de 1981 a 2012, por meio de VEC. O autor observou baixa relevância nas análises de longo prazo, em contraste à maior relevância no curto prazo.

Complementando, na Tabela 5, são apresentadas as estimativas da decomposição da variância dos erros de previsão para o lucro médio e retorno médio trimestrais, mostrando o efeito para um, quatro, oito e 12 trimestres.

Tabela 5

Decomposição da variância dos erros de previsão do Lucro médio (mLPA) e do retorno médio (mRET), trimestrais

\begin{tabular}{ccccc}
\hline \multirow{2}{*}{ Período (trimestres) } & \multicolumn{2}{c}{ Decomposição de mLPA $(\boldsymbol{\%})$} & \multicolumn{2}{c}{ Decomposição de mRET $(\boldsymbol{\%})$} \\
\cline { 2 - 5 } & $\mathrm{mLPA}$ & $\mathrm{mRET}$ & $\mathrm{mLPA}$ & $\mathrm{mRET}$ \\
\hline 1 & 100,00 & 0,00 & 21,92 & 78,08 \\
4 & 81,87 & 18,13 & 34,48 & 65,52 \\
8 & 76,92 & 23,08 & 38,72 & 61,28 \\
12 & 76,47 & 23,53 & 39,29 & 60,71 \\
\hline
\end{tabular}

Fonte: Elaborado pelos autores (2017).

Em relação ao lucro médio, observa-se que depois de quatro trimestres (um ano), o retorno explica $18,13 \%$ do lucro médio, e que após oito e 12 trimestres, o retorno médio explica praticamente a mesma proporção do lucro médio, $23,08 \%$ e $23,53 \%$, respectivamente. A maior parte da explicação do lucro médio é dada pelo próprio lucro.

Por outro lado, em relação ao retorno médio, o lucro médio corresponde a uma parcela mais expressiva da decomposição dos erros da variância, sendo que já no primeiro trimestre, o lucro médio consegue explicar $21,92 \%$ do retorno e, após quatro, oito e 12 trimestres, o lucro explicou acima de $34 \%$ até $39,29 \%$ do retorno. Ou seja, o lucro conseguiu explicar mais do retorno do que o contrário - o que também vai de encontro aos achados de Lopes (2003), que investigou a causalidade entre lucro e retorno e encontrou evidências de que, para defasagens pequenas (um a três períodos), há relação de causalidade no sentido de lucro para retorno, apesar de que essas conclusões não podem ser estendidas, pois foram analisadas somente duas empresas.

\section{CONSIDERAÇÕES FINAIS}

A importância dos lucros trimestrais nas decisões dos investidores e seus aspectos temporais e sazonais incitam pesquisas sobre o tema, porém, no Brasil, como já abordado por Lopes (2002), há poucas contribuições ao estudo empírico da importância da contabilidade no mercado brasileiro. 
O estudo utilizou um modelo econométrico que permite verificar a relação de dependência entre os lucros trimestrais e os retornos da ação, de forma a identificar a direção da causalidade e a magnitude temporal de seus efeitos após as mudanças da Lei $\mathrm{n}^{\circ}$ 6.404, revogada pela Lei n 11.638, de 28 de dezembro de 2007, que introduziu os IFRS no Brasil.

Os resultados rejeitam a $\mathrm{H} 1$, de que há relação de longo prazo entre os lucros trimestrais e o retorno das ações das empresas brasileiras com participações no Ibovespa no período de 2010 a 2016 - ou seja, apontam que não foi encontrado relacionamento de longo prazo. Tal fato difere dos resultados encontrados por Sonza e Kloeckner (2009), porém adere aos resultados encontrados por Pimentel e Lima (2010).

Além disso, rejeitou-se também H2, de que há causalidade entre os lucros trimestrais e o retorno das ações das empresas brasileiras com participações no Ibovespa no período de 2010 a 2016. Mesmo ciente das restrições da pesquisa, tendo em vista a utilização de dados trimestrais de 45 empresas entre 2010 e 2016, os resultados nos permitem concluir que o retorno é mais sensível a mudanças nos lucros trimestrais do que o inverso. $\mathrm{O}$ ajuste da curva de retorno em três anos mostra o efeito negativo inicial, que, depois, passa a não ter mais efeito nenhum.

Os achados desta pesquisa vão ao encontro dos resultados encontrados por Pimentel e Lima (2010), que afirmaram a relação significativa entre os ganhos e os retornos das ações. Porém, em seus resultados a direção da causalidade não é geralmente definida, o que sugere que a relação lucro-retorno deve ser analisada à nível de empresa específica.

Além disso, os resultados deste artigo, mesmo sendo realizados no período pós adoção IFRS, coincidem com os de Foster (1977) e O'Hanlon (1991), nos quais exercem mais influência sobre o retorno das ações do que o contrário. Porém, diferem de Martikainen e Puttonen (1993), pois eles chegaram à conclusão de que são os retornos das ações que influenciam os resultados contábeis e não o contrário.

Lopes (2003) também encontrou relação de causalidade no sentido lucro para retorno, apesar da sua restrição estar no fato de que analisou apenas duas empresas. Costa Jr, Meurer e Cupertino (2007), assim como O'Hanlon (1991), encontraram resultados em que o contábil exerce maior influência sobre o retorno das ações, do que o contrário.

Por meio da decomposição da variância dos erros de previsão do lucro médio e do retorno médio, os resultados mostraram direção da causalidade no sentido de lucros trimestrais para retorno das ações. Além disso, os resultados da função impulso-resposta, que indica que o retorno é mais influenciado por choques do lucro do que o contrário, no período analisado, mostram ajustamento a curto prazo.

Logo, os resultados desta pesquisa apontam que, apesar da rejeição das duas hipóteses, a utilização da decomposição da variância dos erros de previsão do lucro médio das empresas nos revela a influência no retorno das ações que se ajustam no curto prazo, destacando a interferência da informação contábil no preço das ações. Corroborando a indicação de Enders (2010) sobre o uso do instrumental de impulso-resposta, foi possível visualizar a resposta de determinada variável a um choque específico nas inovações (resíduos) do modelo (aumento de uma unidade), enquanto os demais choques permanecem constantes, instrumental este, ainda não muito utilizado nas pesquisas aqui citadas.

Vale ressaltar que, caso houvesse um período maior para a análise, os resultados poderiam ser um indicativo de relação a longo prazo, podendo sugerir, assim, que estudos futuros pudessem aumentar a série analisada.

Como trabalho futuro, pode-se analisar as séries de 1995 a 2016, com a inclusão de um ponto de intervenção em 2010 (momento em que houve a alteração da lei), com o objetivo de aumentar as séries e verificar se os resultados ainda prevalecem ou se haverá mudança significativa, estatisticamente falando, na relação lucro e retorno no período. Por fim, pode-se realizar pesquisas com séries temporais, utilizando dados contábeis e de mercado para elucidar melhor os resultados encontrados. 


\section{REFERÊNCIAS}

Antunes M. T. P., Grecco, M. C. P., Formigoni, H., \& Mendonça Neto, O. R. (2012). A adoção no Brasil das normas internacionais de Contabilidade IFRS: o processo e seus impactos na qualidade da informação contábil. Revista de Economia e Relações Internacionais, 10(20), 5-19.

Ball, R., \& Brown, P. (1968). An empirical evaluation of accounting income numbers. Journal of Accounting Research, 6(2), 159-178.

Ball, R., \& Watts, R. (1972). Some time series properties of accounting income. Journal of Finance, 27, 663-681.

Brugni, T. V., Favero, L. P. L., Flores, E. S., \& Beiruth, A. X. (2015). O vetor de causalidade entre lucro contábil e preço das ações: existem incentivos para a informação contábil seguir o preço no Brasil? Revista Contabilidade Vista \& Revista, 26(1), 79-103.

Caiado, J. (2002). Modelos VAR, taxas de juro e inflação, literacia e estatística. Actas do Congresso da Sociedade Portuguesa de Estatística, Lisboa, Portugal, 10.

Campos, O. V., Lamounier, W. M., \& Bressan, V. G. F. (2012). Retornos das ações e o lucro: avaliação da relevância da informação contábil. Revista de Contabilidade e Organizações, 6(16), 1-38.

Carneiro, F. G. (1997). A metodologia dos testes de causalidade em economia. Série Textos Didáticos, Número 20. Brasília: Departamento de Economia/UnB.

Costa Jr., N. C. A., Meurer, R., \& Cupertino C. M. (2007). Existe alguma relação entre retornos contábeis e retornos do mercado de ações no Brasil? Revista Brasileira de Finanças, 5(2), 233-245.

Costa Jr., N. C. A., Martinez, A., Coelho, R., \& Cupertino, C. M. (2008). Propriedades das séries temporais de lucros trimestrais das empresas brasileiras. Revista de Contabilidade $e$ Organizações, 2(2), 19-35.

Deorce, R., Carrasco Gutierrez, C., Reis, A., \& Castro, E. (2018). Causalidade entre os retornos contábeis e os retornos do mercado de ações brasileiro. Revista Ambiente Contábil, 10(1), $1-20$.

Enders, W. (2010). Applied econometric time series. New York: Wiley.

Foster, G. (1977). Quarterly accounting data: time-series properties and redictive-ability results. Accounting Review, 52(1), 1-21.

Galdi, F. C., \& Lopes, A. B. (2008). Relação de longo prazo e causalidade entre o lucro contábil e o preço das ações: evidências do mercado latino-americano. Revista de Administração, 43(2), 186-201.

Gil, A. C. (2002). Como elaborar projetos de pesquisa (4a ed.). São Paulo: Atlas.

Granger, C. W. J. (1969). Investigating causal relations by econometric models and crossspectral methods. Econometrica, 37(3), 424-438. 
Gujarati, D. N. (2011). Econometria Básica. São Paulo: Bookman.

Jindrichovska, I. (2001). The relationship between accounting numbers and returns: some empirical evidence from the emerging market of the Czech Republic. The European Accounting Review, 10(1), 107-131.

Kothari, S. P. (2001). Capital markets research in accounting. Recuperado em 22 de março, 2019, de http://web.mit.edu/kothari/www

Lev, B., \& Amir, E. (1989). Value Relevance of nonfinancial information: the wireless communications industry. Journal of Accounting and Economics, 22.

Lopes, A. B. (2002). A informação contábil e o mercado de capitais. São Paulo: Pioneira Thomson Learning.

Lopes, A. B. (2003). Testing the relation between earnings and returns using the Grangercausality test: an exploratory study in Brazil. Encontro Brasileiro de Finanças, São Paulo, SP, Brasil, 3.

Marconi, M. A., \& Lakatos, E. M. (2002). Técnicas de Pesquisa (5a ed.). São Paulo: Atlas.

Martikainen, T., \& Puttonen, V. (1993). Dynamic linkages between stock prices, accrual earnings and cash flows: a co-integration analysis. Annals of Operations Research, 45(1), 319-332.

Martins, G. A. (2002). Manual de elaboração de monografias e dissertações (3a ed.). São Paulo: Atlas.

O'Hanlon, J. (1991). The relationship in time between annual accounting returns and annual stock market returns in the U.K. Journal of Business Finance and Accounting, 18(3), 305314.

Oliveira, A. B. S. (2011). Métodos da Pesquisa Contábil. São Paulo: Atlas.

Pimentel, R. C., \& Lima, I. S. (2010). Time-series Properties of Earnings and Their Relationship with Stock Prices in Brazil. Business and Economics Research Journal, 1(4), 43-65.

Santos, E. S. (2012). Impacto Total do Processo de adoção do IFRS nos Resultados das Empresas Brasileiras. Encontro ANPAD, Rio de Janeiro, RJ, Brasil, 36.

Santos, E. S. (2015). Impacto total do IFRS no lucro e patrimônio líquido das empresas brasileiras. BASE-Revista de Administração e contabilidade da Unisinos, 12(3), 225-241.

Sonza, I. B., \& Kloeckner, G. O. (2009). Co-integração entre o lucro contábil e o preço das ações negociadas pela bovespa: um estudo empírico. Encontro Brasileiro de Finanças, São Leopoldo, SP, Brasil, 9.

Tswei, K. (2013). Is transaction price more value relevant compared to accounting information? An investigation of a time-series approach. Pacific-Basin Finance Journal, 21(1), 1062 1078. 
Franciane de Oliveira Alvarenga, Leila Batista Mello, Manoel Vitor de Souza Veloso, Marcelo Alvaro da Silva Macedo

Van Doornik, B. F. N. (2007). Modelagem econométrico-financeira de uma empresa baseada em vetores auto-regressivos: uma aplicação à Petrobras S.A. Dissertação de mestrado em Administração, Universidade Federal de Brasília, DF, Brasil. 